\title{
Development of Standalone Solar Energy Harvesting System with Cascaded H-Bridge Sub-multilevel Inverter
}

\author{
Aneeqa Sattar \\ Student of Master's in Electrical \\ Engineering \\ Mehran University of Engineering \\ and Technology \\ Jamshoro
}

\author{
Mukhtiar Ahmed Mahar \\ Professor of Electrical Engineering \\ Mehran University of Engineering \\ and Technology \\ Jamshoro
}

\author{
Mahwish Memon \\ Student of Master's in Electrical \\ Engineering \\ Mehran University of Engineering \\ and Technology \\ Jamshoro
}

\begin{abstract}
Renewable energy sources are a viable solution to tackle the growing supply and demand gap. They are being favored worldwide for power applications due to their cleanliness and sustainability. Solar energy is considered to be the most abundant renewable energy resource. The solar photovoltaic technology is being adopted for both distributed as well as centralized generation. The output from renewable sources is in DC, it requires conversion to $\mathrm{AC}$ for grid integration and large scale utilization. This conversion is carried out using inverters. Traditional inverters introduced issues like high switching losses, harmonic distortion, and poor-quality output. Multilevel inverters are advanced form of conventional inverters and possess much higher efficiency. In this paper, MATLAB/SIMULINK software is used to model a CHB sub-MLI. The PV panel output is fed to CHB sub-MLI to generate a 15-level AC voltage. The switches are triggered using multicarrier phase opposition disposition PWM. FFT analysis tool is used to calculate the THD which is obtained as $3.11 \%$. MPPT perturb and observe algorithm is employed to guarantee maximum PV output. Consequently, 15-level AC output is generated and fed to the load.
\end{abstract}

\section{General Terms}

Renewable Energy, Multicarrier Pulse Width Modulation, Multilevel Inverter

\section{Keywords}

Solar PV, Cascaded H-Bridge, Multilevel Inverter, THD, MATLAB/SIMULINK

\section{INTRODUCTION}

Rapid population and economic growth, high reliance on fossil fuels and drastic environmental impacts are strong drivers for renewable technology advancement [1] [2]. Fossil fuel consumption may have been economically viable to fulfil the surging energy demand till now, but it is a great environmental threat with dangerous levels of greenhouse gas emissions [3]. Pertaining to these escalating concerns, renewable energy sources have proven to be much better alternatives. Solar energy, among other renewable sources, is regarded the best due to its cleanliness, abundance, availability, and ease of installation [4]. Solar photovoltaic (PV) technology enables direct conversion of sunlight to direct current (DC) electricity. PV systems are preferred for distributed generation over other renewable energy power generation technologies, as they are simpler and more flexible [5]. For the extraction of maximum power from PV systems, perturb and observe $(\mathrm{P} \& \mathrm{O})$ algorithm is employed [6]. The conversion from DC to alternating current is carried out by means of a power converter called inverter.
Traditionally, power conversion was done using inverters with two-level and three-level voltage output [7]. High voltage stress, excessive switching loss, lower efficiency and lowquality output were common problems in these inverters [8]. The multilevel inverter (MLI) concept was first introduced in 1975, to tackle these problems. MLIs were designed to generate more output voltage levels, require lesser components, and possess lower total harmonic distortion (THD) compared to previous versions (Ref). Since then, they have been seen as a viable solution for renewable energy, smart grid, and electrical vehicle (EV) applications [9] [10] [11]. Solar PV systems can be integrated with MLIs for power applications at different levels [12]. Cascaded H-bridge (CHB), diode-clamped (DC) and flying capacitor (FC) are the three basic configurations based on operation strategy. Many advanced topologies have been developed with different functionalities [13]. Various control techniques such as multicarrier pulse width modulation (PWM), space vector, selective harmonic elimination (SHE), etc. are used for triggering these power inverters. Among these, the multicarrier PWM is the most popular due to its simplicity and low THD output [14]. As, higher value of THD degrades the quality of output waveform [15]. This paper proposes a sub-CHB MLI topology integrated with three solar PV cells, each producing a distinct constant voltage. Multicarrier phase opposition disposition (POD) PWM is used for modulation. Further, $\mathrm{P} \& \mathrm{O}$ algorithm is used for maximum power point tracking (MPPT), to ensure maximum power output to the resistive load.

\section{METHODOLOGY}

The proposed model is simulated in MATLAB/SIMULINK software. Power GUI tool is used for FFT analysis to calculate the THD of inverter output voltage. The model parameters are given in table 1 .

Table 1. Model Parameters

\begin{tabular}{|c|c|}
\hline Sine wave frequency & $50 \mathrm{~Hz}$ \\
\hline Switching frequency & $1000 \mathrm{~Hz}$ \\
\hline Output voltage levels & 15 \\
\hline No. of carriers & 14 \\
\hline $\mathrm{R}$ & $250 \Omega$ \\
\hline Switch type & IGBT \\
\hline Switches used & 7 \\
\hline No. of DC voltages & 3 \\
\hline DC voltage magnitude & $V_{1}=12 \mathrm{~V}$ \\
\cline { 2 - 2 } & $V_{2}=24 \mathrm{~V}$ \\
\cline { 2 - 2 } & $V_{3}=48 \mathrm{~V}$ \\
\hline
\end{tabular}




\section{CASCADED H-BRIDGE SUB- MULTILEVEL INVERTER}

The cascaded H-bridge sub-multilevel inverter topology uses a total of seven switches, of which three are responsible for level generation and the rest are for polarity changer circuit, as shown in figure 1 .

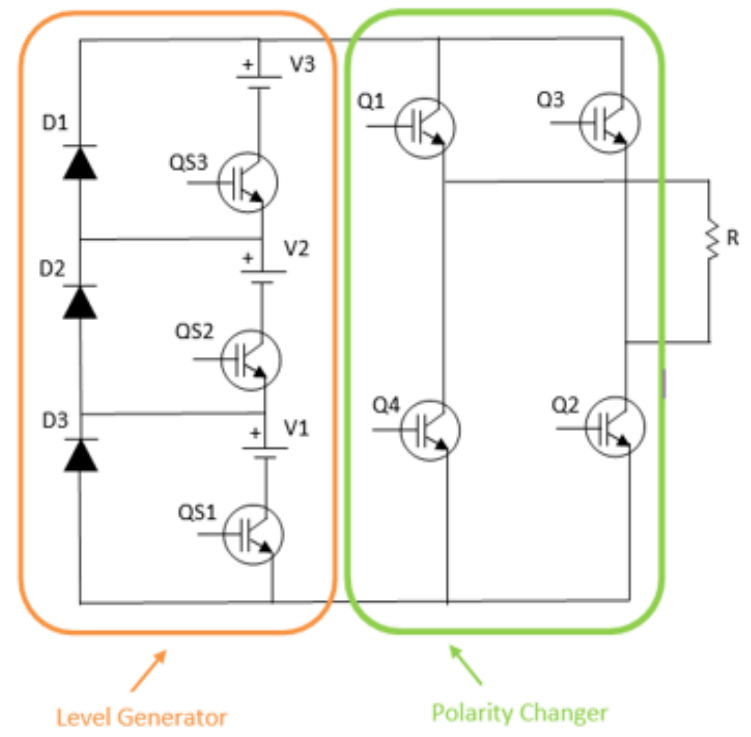

Fig 1: Cascaded H-bridge sub-MLI

The level generation circuit has three dissimilar constant DC voltages each with a diode. This topology is better than the conventional CHB-MLI, as it requires lesser switches for generating equal output levels. The equation or output voltage level with respect to DC voltages is given as:

$$
n_{\text {level }}=2^{n+1}-1
$$

Where:

$n$ indicates the DC voltage outputs from PV

$n_{\text {level }}$ indicates the number of generated output levels

These will be added when the publications are assembled.

\section{SIMULATION MODEL}

\subsection{Power Circuit}

The power circuit consists of three PV panels, each producing a constant DC voltage output. To ensure maximum supply to the load, P \& O algorithm of MPPT control is used. The 15level MLI output is fed to the resistive load. Figure 2 shows the simulation model with PV panels.

\subsection{Control Circuit}

The control circuit is responsible for generating required gating signals to trigger the switches. A generalized control scheme for cascaded multilevel inverter is shown in figure 3.

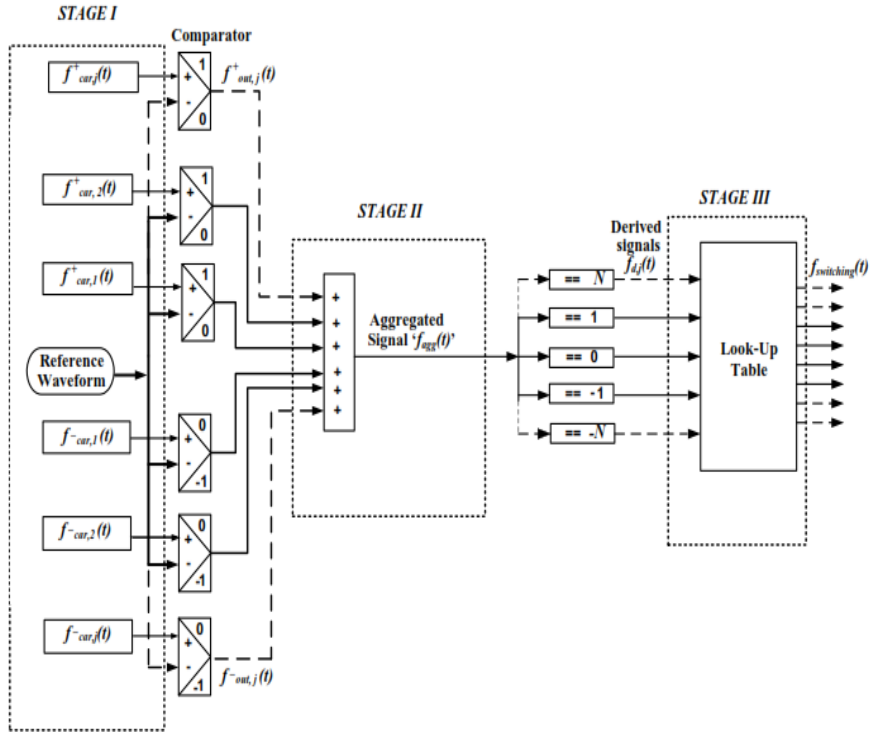

Fig 3: Generalized CHB-MLI control scheme

The control technique used is multicarrier phase POD-PWM. Fourteen carriers are generated, using a combination of comparators, logic, and relational operators. The carrier waveform for POD-PWM can be seen in figure 4 .

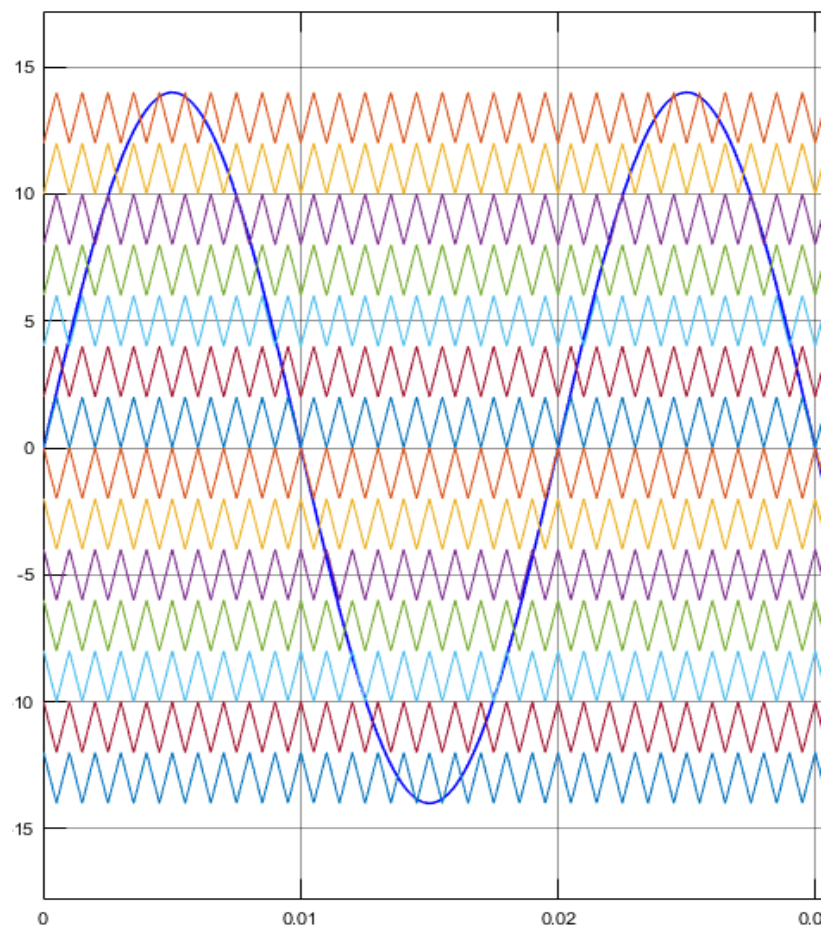

Fig 4: Multicarrier waveform 


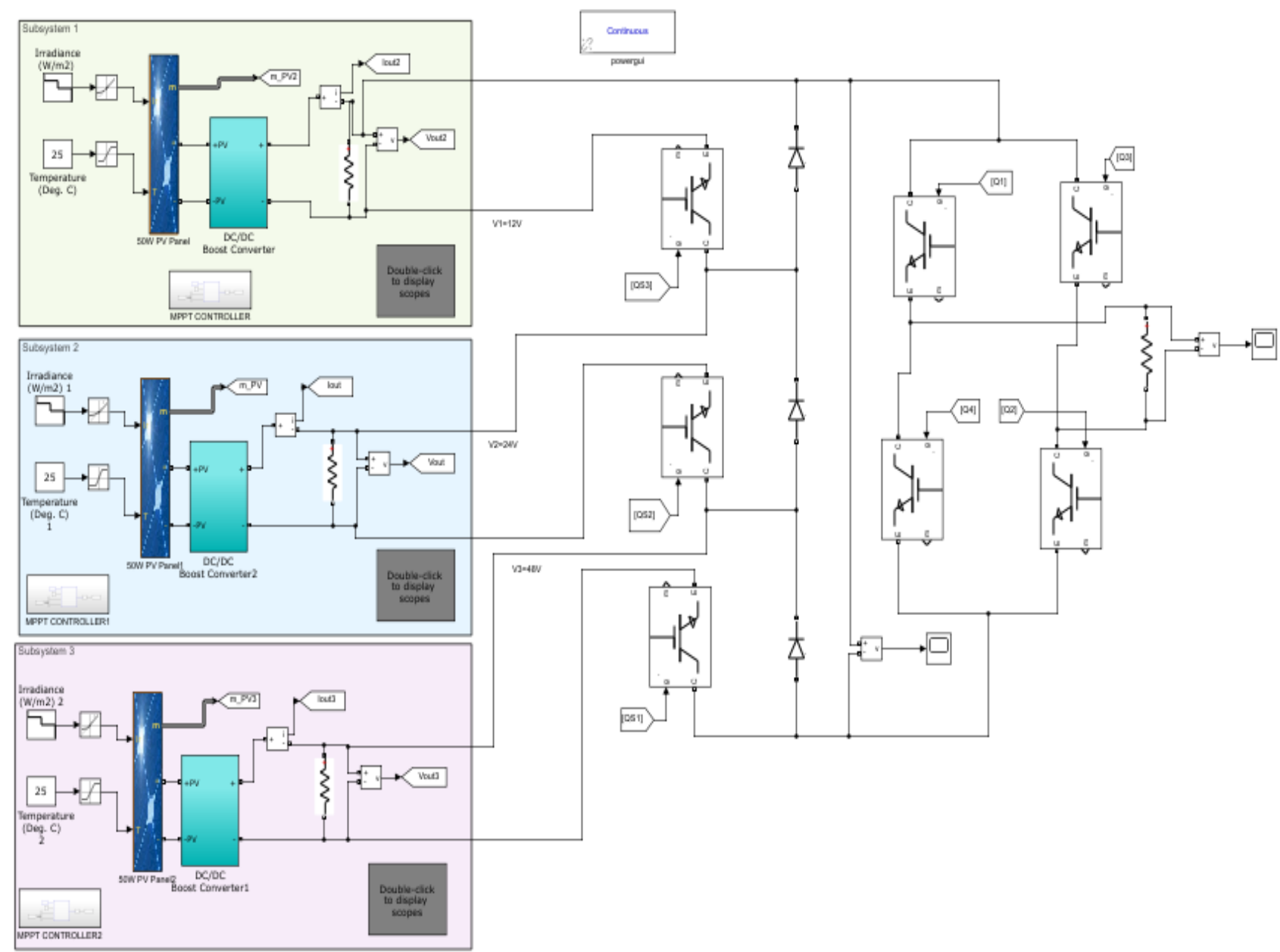

Fig 2: Simulation model for power circuit

\section{RESULTS}

\subsection{Output Voltage}

The 15-level AC voltage output is shown in figure 5. The voltage magnitude is approximately $80 \mathrm{~V} \mathrm{AC}$. Each level in the output voltage is produced with a specific switching sequence. For receiving $\mathrm{V}_{3}$ at the output, switches QS3, Q1 and Q2 are triggered. Similarly, for negative polarity operation, Q3 and Q4 are turned on. In this fashion, a 15-level output is generated.

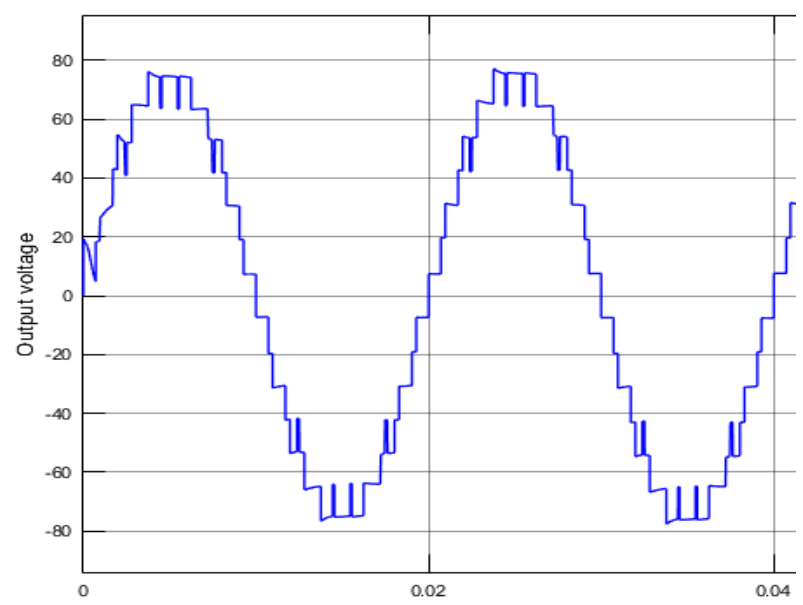

Fig 5: Output voltage

\subsection{THD Analysis}

THD is the measure of harmonic content in the output. The THD is calculated using FFT analysis tool. For multicarrier POD-PWM, the THD at 75.35 is found to be $3.11 \%$, shown in figure 6.

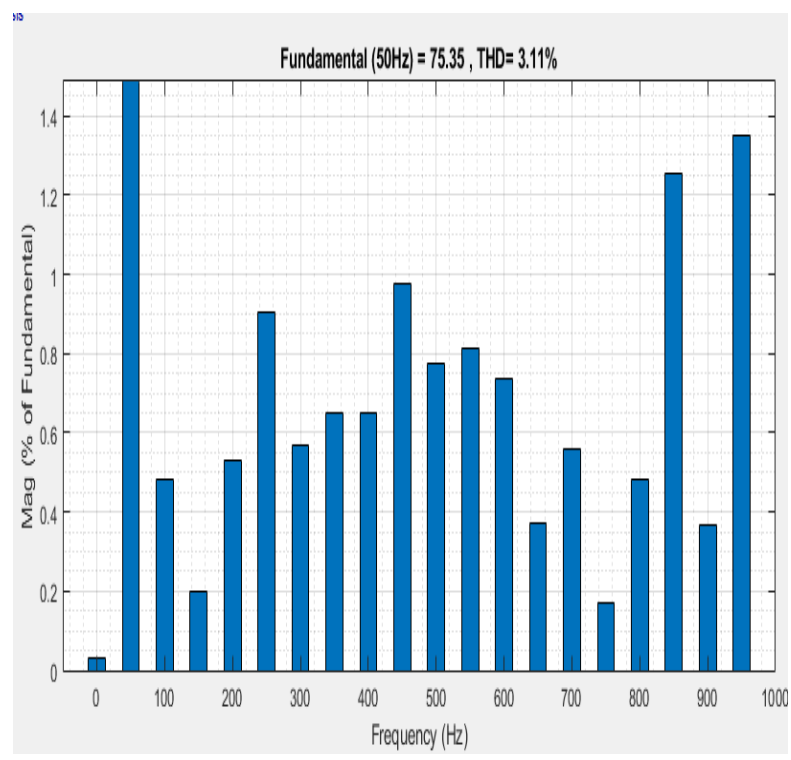

Fig 6: Output voltage THD 


\section{CONCLUSION}

The simulation for sub-CHB MLI has been modelled in MATLAB/SIMULINK using IGBT switches, triggered with multicarrier POD-PWM technique. The output from solar PV panels is made constant with $\mathrm{P} \& \mathrm{O}$ MPPT control algorithm, which is implemented for DC-DC converter. A 15-level stepped AC voltage is generated at the inverter output with reduced THD. The THD is calculated at 75.35 using FFT analysis tool from Power GUI block. The THD is computed as $3.11 \%$. The solar PV system in this research model can be integrated with wind energy for hybrid operation, for sustainable and clean energy production.

\section{ACKNOWLEDGMENTS}

I pay my sincere gratitude to all the authors and faculty of Mehran University of Engineering and Technology for their earnest guidance and support in this research.

\section{REFERENCES}

[1] Ramesh Babu A, Raghavendiran TA, Sivachidambaranathan V, Barnabas Paul Glady J. 2017. Novel cascaded H-bridge sub-multilevel inverter with reduced switches towards low total harmonic distortion for photovoltaic application. international Journal of Ambient Energy.

[2] Seifi, A., Hosseinpour, M., Dejamkhooy, A., Sedaghati, F. and Ostad, E., 2019. A New Generalized Multilevel Converter Topology Based on Cascaded Connection of Basic Units. IEEE Journal of Emerging and Selected Topics in Power Electronics, 7(4), pp. 2498-2512.

[3] Sharif, A., Meo, M.S., Chowdhury, M.A.F. and Sohag, K., 2021. Role of solar energy in reducing ecological footprints: An empirical analysis. Journal of Cleaner Production, Volume 292.

[4] Rajani, B. and Kommula, B.N., 2021. A decisive evaluation of series connected-hybrid modulated inverter for EV applications. s.l., s.n.

[5] Soomro, F., Mahar, M.A. and Larik, A.S., 2021. Design a Switched DC Sources based Multilevel Inverter for PV System. International Journal of Computer Applications, 183(1).

[6] Sarkar, I. and Fernandes, B.G., October. 2014. Modified Hybrid Multi-Carrier PWM Technique for Cascaded HBridge Multilevel Inverter. Texas, USA, s.n.
[7] Janardhan, K., Mittal, A. and Ojha, A., 2020. Performance investigation of stand-alone solar photovoltaic system with single phase micro multilevel inverter. Energy Reports, Volume 6, pp. 2044-2055.

[8] Hussan, M.R., Sarwar, A., Siddique, M.D., Mekhilef, S., Ahmad, S., Sharaf, M., Zaindin, M. and Firdausi, M., 2020. A Novel Switched-Capacitor Multilevel Inverter Topology for Energy Storage and Smart Grid Applications. Electronics, 9(10).

[9] Kahia, M., Aïssa, M.S.B. and Lanouar, C., 2017. Renewable and non-renewable energy use - economic growth nexus: The case of MENA Net Oil Importing Countries. Renewable and Sustainable Energy Reviews, Volume 71, pp. 127-140.

[10] Solangi, M.H., Mahar, M.A., Larik, A.S. and Mahessar, M.R., 2020. Design a Perturb \& Observe MPPT Algorithm for PV System Based Asymmetric Cascaded Half-Bridge Multilevel Inverter. Indian Journal of Science and Technology, 13(4), pp. 439-452.

[11] Dogga, R. and Pathak, M.K., 2019. Recent trends in solar PV inverter topologies. Solar Energy, Volume 183, pp. 57-73.

[12] Sunddararaj, S.P. and Srinivasarangan Rangarajan, S. 2020. An Extensive Review of Multilevel Inverters Based on Their Multifaceted Structural Configuration, Triggering Methods and Applications. Electronics, 9(3).

[13] Ahmed, T.A., Mohamed, E.E., Youssef, A.R., Ibrahim, A.A., Saeed, M.S. and Ali, A.I., 2020. Three phase modular multilevel inverter-based multi-terminal asymmetrical DC inputs for renewable energy applications. Engineering Science and Technology, an International Journal, 23(4), pp. 831-839.

[14] Najafi, E. and Yatim, A.H.M., 2011. Design and implementation of a new multilevel inverter topology. Design and Implementation of a New Multilevel Inverter Topology. EEE Transactions on Industrial Electronics, 59(11), pp. 4148-4154

[15] Mahar, M.A., Uqaili, M.A. and Larik, A.S., 2011. Harmonic Analysis of AC-DC Topologies and their Impacts on Power Systems. Mehran University Research Journal of Engineering and Technology, 30(1). 